\title{
The Effect of Inferencing Tasks on Low-Proficiency Korean EFL Learners' Learning Vocabulary From Movies
}

\author{
Lee, Jin Hyung \\ (Korea University)
}

\begin{abstract}
Lee, Jin Hyung. (2018). The effect of inferencing tasks on low-proficiency Korean EFL learners' learning vocabulary from movies. STEM Journal, 19(4), 71-90.
\end{abstract}

\begin{abstract}
This study explored the effect of a lexical inferencing task on low-proficiency Korean EFL learners' vocabulary acquisition from watching a movie. A total of 63 Korean freshman students enrolled in three different sessions of a compulsory English course for low proficiency level students participated in the two-week-long study. Each session was randomly designated as a viewing group, an instruction group, and an inference group. After watching an English movie, the participants' gain in their lexical knowledge for twenty target vocabulary items from the movie was assessed. While the viewing group received no other treatment, the instruction group was explicitly taught the target vocabulary and the inference group completed a lexical inferencing task for the target words prior to watching the movie. In the posttest, the participants in all three groups showed a significant gain in their lexical knowledge, with the greatest improvement demonstrated by the inference group. The viewing group and the instruction group did not show any significant difference in their lexical development. Based on the results, this study suggests that i) movies are useful resources for L2 vocabulary learning and ii) a lexical inferencing task is a valuable supplement for foreign language classrooms employing movies in the curriculum.
\end{abstract}

\section{INTRODUCTION}

English movies are popular educational resources in language classrooms for EFL learners. While providing rich authentic linguistic input, movies highly motivate learners to become familiar with the language and culture of English-speaking countries (see Chapple \& Curtis, 2000; Herron, Morris, Secules, \& Curtis, 1995; Kim, 2006; Stephens, 2001). In addition to offering EFL learners "an accessible window" into the target culture (Stephens, 2001, p. 2), they are found to be effective for developing various language skills. Especially, a major strand of research focuses on the effect of movies on facilitating 
language learners' listening comprehension or communicative competences (Ismaili, 2013). Movies play an important role as a facilitator for vocabulary acquisition as well. According to Yum and Kahng (2007), movies help enhance the lexical knowledge of English learners of all proficiency groups. However, utilizing movies as a source for vocabulary acquisition in classrooms can be a challenge due to the limited encounters with new words in a single movie (see Webb, 2010). While Joe (1998) found that actively listening to a group discussion could lead to vocabulary learning, the chance of incidental learning of vocabulary through listening seems quite low. Even with reading, around twenty encounters with a novel word are expected for incidental learning of vocabulary to take place (Waring \& Takaki, 2003). In order to compensate such drawback, supplementing movies with efficient and appropriate tasks for vocabulary acquisition would be necessary.

Vocabulary acquisition constitutes a significant part of language learning. The area of lexical instruction was once relegated as many believed vocabulary learning takes place on its own (Nation, 1990). However, with the enhanced awareness of the importance of lexical knowledge which forms the basis of the four skills of language performance, finding efficient ways to teach and learn vocabulary has risen as a challenging task for many EFL teachers. A variety of vocabulary learning strategies including making use of dictionaries, mnemonics, word parts and key words have been introduced in language classrooms (Nation, 2001). For lexical growth, contextualized learning of vocabulary is desirable as learners acquire words by making guesses as to their definitions based on the given cues in the context (Oxford \& Scarcella, 1994). Nation and Meara (2010) see such lexical inferencing strategy as the most efficient way to develop language learners' lexical knowledge. In Fraser's (1999) study of ESL students' use of lexical processing strategies in the encounter of new words, learners preferred to infer the words rather than ignore or consult them. Compared to Krashen's (1989) and Hulstijn's (1992) studies which showed around $7 \%$ of retention rate of vocabulary acquired without lexical inferencing attempts, the participants in Fraser's experiment displayed higher retention rate of about $31 \%$ with the utilization of inference skills.

Considering the motivating and entertaining nature of movies, they may serve as a useful resource for second language vocabulary learning, especially if it is supplemented by lexical inferencing method which is likely to facilitate vocabulary learning from movies. In this light, the present study was designed to explore the effect of L2 lexical inferencing on vocabulary acquisition from watching a film. The two following research questions are addressed here:

1. Do EFL learners acquire vocabulary from watching an English film? 
2. Is a lexical inferencing task efficient for EFL learners' vocabulary acquisition from watching an English film?

\section{LITERATURE REVIEW}

\section{Multimedia as English Learning Resources}

The effect of multimedia sources on learners' linguistic development has attracted a great deal of attention. Especially, extensive attention has been paid on the positive impact of films and other multimedia sources on developing listening skills (Ginther, 2002; Gruba, 2006; Watts, 1989) as well as oral communicative skills (Borrás \& Lafayette, 1994). According to Richards (1985), multimodal processing of language promotes listening ability as it helps with the subskills of listening including the ability to discriminate the sounds of the target language, to grasp accents and rhythm, and to understand different speech styles and rates. Regarding the improvement of communicative skills, the multimedia environment leads to an increase in the amount of communicative discourse as learners are likely to become more active in using the target language (Johnstone \& Milne, 1995). In addition to facilitating the development of linguistic skills, multimedia sources lead to better learning from the psychological perspective (Gilakjani, 2012). The use of multimedia sources can be effective for lowering the anxiety level of language learners (see Hwang \& Huang, 2010). By applying multimedia to language teaching, it is possible to create "a relaxing and non-threatening learning environment in which learners' motivation and self-esteem can be promoted and learners' anxiety can be reduced" (Warschauer, 1997, p. 478). In the similar vein, Ogata, Matsuka, El-Bishouty, and Yano (2009) emphasized how multimedia sources may provide the favorable learning environment for language learners. The authenticity of the material from the multimedia sources also guides learners to become accustomed to the cultural aspects of the target language (Herron et al., 1995).

The use of multimedia sources has a positive impact on learners' vocabulary acquisition as well. According to Kwak (2004), elementary school students who watched English animated movies showed a significant gain in their lexical knowledge. They watched an animated film for twenty minutes and completed various activities including role-plays and puzzles. In the posttest, the students showed a great improvement in their listening comprehension and lexical knowledge. Yang and Kim (2010) focused on the value of American television dramas in helping viewers get familiar with English vocabulary. The researchers selected and analyzed the contexts for the use of the target vocabulary in four different American dramas to suggest them as an efficient vocabulary learning material. 
However, for the studies of lexical development, the primary focus has been limited to the effects of subtitles (see Etemadi, 2012; Gorjian, 2014; Harji, Woods, \& Alavi, 2010; Hayati \& Mohmedi, 2011). The L2 subtitles for the multimedia sources aid learners' acquisition of novel words and thus play an important role in improving their comprehension of the content (Bird \& Williams, 2002). With subtitled sources, language learners acquire vocabulary and gain a better understanding of authentic texts from their exposure to the printed text in addition to the aural and visual input (Baltova, 1999). Such sources are useful for helping language learners recognize new words as well. In his experiment with advanced ESL students, Markham (1999) found that the availability of subtitles for educational television programs significantly improved their ability to recognize vocabulary which led to increased comprehensibility of English videos. In addition to the acquisition of single words, Wilson (2000) highlighted the role of subtitled movies in facilitating language learners' recognition of unknown idioms. Other researchers focused on comparing different methods of providing subtitles. Hsu, Hwang, Chang, and Chang (2013) compared the effects of providing subtitles for the target words only and for the entire video. In their study, Taiwanese students were assigned to three groups: a control group, a target-word group, and a full-caption group. For the participants in the target-word group, English captions and Chinese subtitles were provided only for the target words whereas for the full-caption group, full English captions were given for the whole video. Both the target-word group and the full-caption group outperformed the control group, illustrating the effectiveness of subtitles in EFL learners' vocabulary acquisition. In a study of Dutch children's vocabulary acquisition from watching a documentary, they learned new words most efficiently when watching L1 subtitled version (Koolstra \& Beentjes, 1999). The usefulness of employing multimedia sources for second language vocabulary acquisition needs to be explored in more diverse perspectives.

\section{Vocabulary Learning and Lexical Inferencing}

Vocabulary is a key issue in second language acquisition especially with listening comprehension (see Lee \& Cai, 2010). For language learners, developing skills to manage the novel words is necessary. When encountering unfamiliar words, language learners employ a variety of strategies. Lexical inferring is believed to be the most efficient strategy of all (Nation \& Meara, 2010). Haastrup (1991, p. 40) defines lexical inferencing as making "informed guesses" about the meaning of the lexical item using linguistic and contextual cues as well as the learner's knowledge of language and the general world. Similarly, Carton (1971, p. 45) explains how language learners utilize the "attributes and contexts" of the words they are familiar with in order to infer the meanings of new words. Lexical inferencing accounts for much of vocabulary development in first language 
acquisition (Nagy, Herman, \& Anderson, 1985). According to Nagy et al. (1985), L1 learners acquire the information for approximately $10 \%$ of the novel words encountered in a text, and from such inferencing behavior, they are estimated to learn around 1,000 words or more per year. For such reason, L2 learners' lexical inferencing behavior has been of many researchers' interest (Fraser, 1999; Hulstijn, 1992; Morrison, 1996; Nassaji, 2003; Paribakht \& Wesche, 1999). To infer new words, language learners use their linguistic and general world knowledge in addition to the contextual cues (Goh, 2002). Especially with low-frequency words, it is the meaningful context that plays a major role in language users' comprehension of the text (Wittrock, Marks, \& Doctorow, 1975). As Carton (1971) explains, more contextual clues lead to a greater chance for learners to identify and process new words. In a study of lexical inferencing in an EFL setting, Chinese learners of English employed different strategies such as parallelism, sentencebound cues, forward cues, and backward cues to guess the meaning of unknown words (Chern, 1995).

Learners' L2 proficiency plays an important role in their success of lexical inferencing (Fraser, 1999; Haastrup, 1991; Morrison, 1996). The focus of research on lexical inferencing has been on high-proficiency L2 learners who are found to be successful guessers for unfamiliar vocabulary encountered in a text (Fraser, 1999; Morrison, 1996). According to Fraser, high-proficiency learners make more attempts to infer the meanings of new words with higher accuracy compared to low-proficiency learners. Similarly, O'malley, Chamot and Küpper (1989) found out how more proficient language users are better at employing cognitive strategies to make an inference of the meaning of unfamiliar words that play a crucial role in comprehension of the task. The link between lowproficiency learners and their lexical inferencing behavior, however, has been neglected, possibly due to their lack of ability to draw on the contextual cues given in L2 (Haastrup, 1991; Haynes, 1995). Considering the effect of lexical inferencing tasks for proficient learners, exploring ways to promote efficient inferencing behavior for low-proficiency learners seems necessary.

\section{METHOD}

\section{Participants}

The experiment was carried out in October 2016. Sixty-three first-year college students participated in the study. All participants were female students between 18 and 22 years old. They were all native speakers of Korean, and no participant had experience of studying or living abroad in English-speaking countries. The students were enrolled to 
"Basic English", which is a compulsory course for all freshman students of the department. They were randomly distributed into one of the three sessions upon their entrance to the college. The researcher instructed all three sessions and randomly assigned each session as a viewing group, an instruction group, and an inference group for the study. Based on their average TOEIC score ${ }^{1}$, the participants can be labelled as being low-proficiency speakers of English. Table 1 summarizes the demographic information of the participants.

TABLE 1

Demographic Information of the Participants

\begin{tabular}{cccc}
\hline \hline & Viewing Group & Instruction Group & Inference Group \\
\hline Number of participants & 20 & 23 & 20 \\
Mean TOEIC score & $481.3(120.3)$ & $477.8(117.2)$ & $487.0(86.26)$ \\
\hline
\end{tabular}

Note. The numbers in brackets indicate standard deviation of the mean.

\section{Materials}

Zootopia (Howard \& Moore, 2016), an approximately 100 minute-long American animated film, was used as the target text in this study. Twenty-three participants answered they have previously watched the film. The movie was selected on the basis of the proficiency level of the participants, as the general vocabulary level of the film was considered appropriate for their low-intermediate level by the researcher. As Shim and Baik (1997) emphasized, it is important that language used in movies is suitable for the proficiency level of language learners. Twenty target vocabulary items ${ }^{2}$ which were highly likely to be unfamiliar to the participants were selected from the movie. To make sure the target words are novel to the participants, vocabulary words that are not listed as top 1,000 most frequent English words based on the Corpus of Contemporary American English $(\mathrm{COCA})^{3}$ were selected as the target items.

\section{Design}

The experiment took two weeks. In the first week of the experiment, each group watched the whole movie at their allotted time slots. All groups performed the pretest for ten minutes prior to watching the film. The pretest contained twenty target vocabulary

1 The TOEIC score can be interpreted in terms of the level of the CEFR (Common European Framework of Reference for Languages) which provides the foundation for describing the language skills required to reach different levels of linguistic proficiency. According to ETS, English speakers whose TOEIC score ranges from 225 to 560 are at A2 level on a six-level scale of CEFR, which is the level for "basic users" of English.

2 The target items are found in the Appendix.

3 The word list can be obtained from https://www.wordfrequency.info/intro.asp. 
items, and the participants were asked to provide the L1 translation for the words. For all groups, the movie was shown with the Korean subtitle. While the viewing group watched the movie after submitting the pretest, the instruction group and the inference group each received different treatments before watching the movie. For the instruction group, the instructor provided an explicit lesson on the vocabulary tested in the pretest. For around twenty minutes, the instructor explained what each target word means in Korean and provided example sentences containing each word. The example sentences were made by the instructor. The inference group was given a worksheet for lexical inferencing task containing three excerpts from the movie script ${ }^{4}$ with the twenty target words bolded and underlined. The participants in the inference group were instructed to read the excerpts and make their best guesses for each lexical item based on the context. The participants were given twenty minutes to complete the task. Conversation 1 presents one of the excerpts included in the inference task. After completing the task, the instructor gave the participants the L1 translations for the words.

[In the café, the owner, Jerry Jumbeaux, Jr., an elephant, is at the counter taking orders. Judy enters and sees Nick talking to Jerry.]

Jerry Jumbeaux Jr.: Look, you probably can't read, fox, but the sign says, "We reserve the right to refuse service to anyone", so beat it!

[Judy steps forward]

Judy Hopps: Well, I don't wanna cause you any trouble but, I believe (1)

scooping ice cream with an ungloved trunk is a class-three health code (2)

violation. Which is kind of a big deal. Of course I can let you off with a (3)

warning if you glove those trunks and, I don't know, finish selling this nice dad and his son a... [to Nick] What was it?

Nick Wilde: A jumbo pop. Please. (...) Thank you so much. Oh no, are you kidding me? I don't have my wallet! I'd lose my head if it weren't (4) attached to my neck. Thanks anyway.

(Conversation 1, Zootopia)

In the second week of the experiment, the participants completed the posttest containing the twenty target items. No prior announcement was given regarding the administration of the posttest. Table 2 presents the experiment procedure for each group.

${ }^{4}$ The script for the movie Zootopia is available at https://www.imsdb.com/scripts/Zootopia.html. 
TABLE 2

Experiment Procedure

\begin{tabular}{cccccc}
\hline \hline Week & Step & Duration & Viewing Group & Instruction Group & Inference Group \\
\hline 1 & 1 & 10 minutes & Pretest & Pretest & Pretest \\
& 2 & 20 minutes & - & Vocabulary lesson & Inference task \\
& 3 & 100 minutes & Movie viewing & Movie viewing & Movie viewing \\
2 & 4 & 10 minutes & Posttest & Posttest & Posttest \\
\hline
\end{tabular}

\section{Data Analysis}

The data obtained for this study were analyzed using the SPSS 21 package program. Descriptive statistics were computed for the analysis of overall mean scores of pretest and posttest. To address the first research question, participants' gain of lexical knowledge was assessed using the paired t-tests comparing their performance on the pretest and posttest. For the second research question regarding the difference in the improvement of lexical knowledge across the three groups, a one-way ANOVA was conducted. Finally, a post hoc analysis was computed to compare the extent of the effect of instruction and inference task in relation to the viewing group as well as to each other.

\section{RESULTS AND DISCUSSION}

\section{Results}

1) The Gains in Participants' Lexical Knowledge Within Groups

Prior to analyzing the data, the credibility of the target items was measured using Cronbach's alpha. The reliability coefficient for the items was .714, which is an acceptable figure according to the criteria ${ }^{5}$. The descriptive statistics of the overall mean scores for the pretest and the posttest are presented in Table 3.

TABLE 3

Descriptive Statistics of the Overall Mean Scores

\begin{tabular}{|c|c|c|c|c|c|c|c|}
\hline & \multicolumn{2}{|c|}{ Pretest } & \multicolumn{2}{|c|}{ Posttest } & \multirow[b]{2}{*}{$t$} & \multirow[b]{2}{*}{$d f$} & \multirow[b]{2}{*}{$p$} \\
\hline & $M$ & $S D$ & $M$ & $S D$ & & & \\
\hline $\begin{array}{l}\text { Viewing Group } \\
(n=20)\end{array}$ & 20.00 & 13.3771 & 24.25 & 16.2444 & -2.03 & 19 & .050 \\
\hline $\begin{array}{l}\text { Instruction Group } \\
\qquad(n=23)\end{array}$ & 19.1304 & 15.1247 & 30.65 & 19.0874 & -5.99 & 22 & .000 \\
\hline
\end{tabular}

5 According to the criteria, the internal consistency for the value of $.8>\alpha \geq .7$ is considered acceptable. 


\begin{tabular}{cccccccc}
\hline $\begin{array}{c}\text { Inference Group } \\
(n=20)\end{array}$ & 19.5000 & 13.0686 & 46.75 & 19.2131 & -8.32 & 19 & .000 \\
\hline
\end{tabular}

Each of the twenty vocabulary items is worth $5 \%$ to comprise the total score of $100 \%$. In order to test for a statistically significant difference between the means of the pretest and posttest for each group, the paired t-tests were used. The alpha level for the analyses in this study was set at 0.05 . The analysis showed that all three groups showed significant improvement from the pretest to the posttest $(t=-2.03, p<.05$ for the viewing group; $t=$ -5.99, $p<.001$ for the instruction group; $t=-8.32, p<.001$ for the inference group).

To account for the higher figures of standard deviation of the posttest results compared to those of the pretest across all groups, the correlation between the participants' TOEIC scores and their pre- and post-test results was examined by conducting the Pearson correlation test. The correlation results are presented in Table 4.

TABLE 4

Correlations of Participants' TOEIC Scores and Pre- and Post-Test Results

\begin{tabular}{cccc}
\hline \hline & $S S$ & $r$ & $p$ \\
\hline Viewing group & 22543.75 & .607 & .005 \\
Instruction group & 29181.52 & .748 & .000 \\
Inference group & 16280.00 & .517 & .020 \\
\hline
\end{tabular}

According to the analysis, all three groups showed a positive correlation between their TOEIC scores and their performance on the pre- and post-tests, and such correlations are significant $(r=.607, p<.01$ for the viewing group; $r=.748, p<.001$ for the instruction group; $r=.517, p<.05$ for the inference group).

\section{2) The Gains in Participants' Lexical Knowledge Across Groups}

The data for the gains in participants' lexical knowledge from the pretest to the posttest across the three groups were analyzed using the one-way ANOVA. As presented in Table 5 , the analysis showed no significant difference in the pretest score between groups, signifying that the participants in all groups had similar lexical competence prior to the experiment.

TABLE 5

The ANOVA Results for the Pretest

\begin{tabular}{cccccc}
\hline \hline & $S S$ & $d f$ & $M S$ & $F$ & $p$ \\
\cline { 2 - 6 } Between groups & 8.106 & 2 & 4.053 & .21 & .979 \\
Within group & 11677.609 & 60 & 194.627 & & \\
\hline
\end{tabular}


In the posttest, a highly significant difference was found between groups $(F=8.091, p$ $<.01)$ as presented in Table 6 .

TABLE 6

The ANOVA Results for the Posttest

\begin{tabular}{cccccc}
\hline \hline & $S S$ & $d f$ & $M S$ & $F$ & $p$ \\
\cline { 2 - 6 } Between groups & 5405.695 & 2 & 2702.848 & 8.091 & .001 \\
Within group & 20042.717 & 60 & 334.045 & & \\
\hline
\end{tabular}

In order to identify the factor contributing to such difference across the groups, a post hoc analysis was computed (see Table 7).

TABLE 7

Post hoc Analysis for the Significance of Gains in Lexical Knowledge Across Three Groups

\begin{tabular}{cccc}
\hline \hline Groups & $M D$ & $S E$ & $p$ \\
\hline Viewing - Instruction & 6.402 & 5.588 & .490 \\
Viewing - Inference & 22.500 & 5.780 & .001 \\
Instruction - Inference & 16.098 & 5.588 & .015 \\
\hline
\end{tabular}

There was no significant difference in the gains of lexical knowledge between the viewing group and instruction group. Highly significant differences were found between the inference group and each of the other two groups $(p<.01$ for the comparison of the inference group and the viewing group; $p<.05$ for the comparison of the inference group and the instruction group).

\section{Discussion}

The first research question investigated the usefulness of a movie as an educational tool for EFL learners' vocabulary learning. All three groups showed a significant gain in their lexical knowledge after watching the movie (see Table 3). As indicated by the analysis of the paired t-tests, the improvement in the performance of the viewing group which received no other treatment except for the movie viewing represents the usefulness of movies for language learners' lexical development $(p<.05)$. Despite the significance of the results, however, the viewing group showed low degree of improvement in their lexical knowledge from the pretest to the posttest $(M D=4.24)$. The participants' low proficiency level of the target language may account for such result. As indicated by their mean TOEIC score (see Table 1), the participants of the current study are low proficiency learners of English. It is highly likely that they were unfamiliar with many of the words appearing in the movie, which could have affected their learning of the target words. According to Webb and Rodgers (2009), L2 viewers need to have a minimum vocabulary size of the 
most frequently occurring 3,000 English word families for the coverage of $95 \%$ of the words in a movie, which is crucial for adequate aural comprehension of the movie. Another possible interpretation is the participants' limited encounters with the target vocabulary while watching a movie. Previous research has emphasized the importance of repeated encounters with unknown words for successful incidental vocabulary learning (Keating, 2008; Rott, 1999; Waring \& Takaki, 2003; Webb, 2007). According to Rott (1999), at least six encounters with the target word is necessary for learning to take place. However, viewers are likely to experience only limited number of encounters with new words in a single movie. Most of the target words in the current study occurred fewer than three times throughout the movie ${ }^{6}$. Regardless of the limited number of encounters with the target words, however, the viewing group displayed the development in their lexical knowledge. Such result supports the previous research which focused on the educational value of movies for language learners. While the earlier studies investigated their facilitation of listening, oral and other psychological factors, the focus was placed on the lexical development in the current study. This study shows that the positive impact of movies reaches beyond such aspects to embrace language learners' lexical gain. As Nation (2001) highlighted, L2 learners lack the opportunity to experience incidental learning of vocabulary compared to native speakers. By utilizing movies of the target language in classrooms, learners can be provided with an environment for successful incidental learning of vocabulary, which may lead to substantial cumulative learning of vocabulary.

While the majority of the participants showed an improvement in their lexical knowledge after the experiment, greater gains were witnessed with the participants with their TOEIC scores above the average across all groups. As indicated in Table 4, a strong correlation was found between the participants' TOEIC scores and the results of their preand post-tests. Regardless of the type of treatments each group received, participants with their TOEIC scores above the average performed significantly better on the posttest across all groups compared to participants with their TOEIC scores below the average. Based on such result, language learners' proficiency level appears to play a major role in their acquisition of vocabulary from movies as well as from explicit teaching and inferencing tasks in combination with movies.

Despite the limited encounters with the target vocabulary, L2 learners may have a better chance for vocabulary acquisition from watching an unmodified, authentic movie if it is supplemented by a vocabulary activity. To explore such hypothesis, the second research question proposes to test for the usefulness of a lexical inference task in comparison to the explicit teaching method. As illustrated in Table 6, a significant difference was witnessed

\footnotetext{
${ }^{6}$ Except for the words savage, mammal, predator and crack, all target words occur fewer than three times
} throughout the movie. 
in the posttest results across the groups, suggesting the varying degrees of effect of each treatment. The post hoc analysis was conducted to compare the extent of the effect of each treatment (see Table 7). The comparison between the viewing group and instruction group showed no significant difference in their performance on the posttest. In other words, the participants who were explicitly taught the target vocabulary words prior to watching the movie did not perform significantly better than the ones who watched the movie without any treatment in the posttest administered a week after the movie viewing session. Based on the result, direct teaching method does not seem very efficient for facilitating vocabulary learning from movies. The inference group, however, showed a highly significant difference from the other two groups in terms of their gain of lexical knowledge ( $p<.01$ for the comparison between the inference group and the viewing group; $p<.05$ for the comparison between the inference group and the viewing group). The twentyminute long inference task containing the excerpts from the movie played a significant role in helping the learners learn and retain the target words from the movie. Given that the participants were unware of the administration of the posttest and that there was a oneweek time interval between the administration of the treatments and the posttest, such improvement in their vocabulary knowledge seems meaningful. The results corroborate the earlier findings on the benefit of lexical inferencing tasks for L2 vocabulary learning (Fraser, 1999; Nassaji, 2003; Nation \& Meara, 2010). Based on the results of the present study, combining lexical inferencing tasks with the application of multimedia sources in language classrooms seems desirable for learners' vocabulary development.

While most of the previous research focused on advanced learners' lexical inference abilities, the current study showed how low-proficiency EFL learners may also benefit from their inferencing skills to learn new vocabulary. As Vandergrift (1997) asserted, even novice learners are able to use the contextual cues to infer unfamiliar words. When less proficient EFL learners face problems inferring meanings due to their weak linguistic processing ability, they utilize their general world knowledge to process their inferencing behavior (Cai \& Wu, 2005). For such reasons, active learning of vocabulary such as inferencing seems more favorable than explicit teaching even with low-proficiency EFL learners. As presented in Table 7, the inference group significantly outperformed the instruction group in the posttest $(p<.05)$, illustrating the efficiency of lexical inferencing tasks for learning vocabulary from movies. For EFL teachers who utilize multimedia sources as their teaching resources, they may expect a positive impact on their students' lexical development by incorporating inferencing activities using the target vocabulary prior to showing them the sources. 


\section{CONCLUSION}

This study has sought to explore the usefulness of English films for low-proficiency EFL learners' vocabulary learning especially in combination with lexical inference tasks. The experiment was designed with three groups: a viewing group, an instruction group, and an inference group. While learners' vocabulary learning solely from watching a movie was assessed for the viewing group, the effect of explicit teaching of the target vocabulary and the lexical inferencing task were each assessed based on the performance of respective groups. The results indicate that EFL learners are able to learn new vocabulary from watching movies. Carrying out lexical inferencing tasks and watching the movies together seems to yield better potential for vocabulary learning. In addition, the study shows that lexical inferencing tasks may benefit EFL learners across all levels; even low-proficiency learners were able to gain considerable amount of lexical knowledge from their lexical inferencing behavior in comparison to others who simply watched a movie or were explicitly taught the target vocabulary from the movie. Based on the results of this study, it can be suggested that teachers consider providing learners an opportunity to work on simple lexical inferencing tasks prior to watching movies or other types of multimedia sources in order to promote the development of deeper lexical knowledge for language learners.

There are few limitations to the approaches taken in the current study. The posttest was administered only once to assess the performance of the groups. The administration of a delayed posttest would be helpful for exploring the long-time effect of the combined approach of watching a movie and doing a lexical inferencing task on improving lexical knowledge. In further studies, adding a comparison group to work on the lexical inferencing task without watching the movie may clearly show the positive impact of the combined approach of lexical inferencing tasks and movies compared to the lexical inferencing tasks alone.

\section{REFERENCES}

Baltova, I. (1999). Multisensory language teaching in a multidimensional curriculum: The use of authentic bimodal video in core French. Canadian Modern Language Review, 56(1), 31-48.

Bird, S. A., \& Williams, J. N. (2002). The effect of bimodal input on implicit and explicit memory: An investigation into the benefits of within-language subtitling. Applied Psycholinguistics, 23(4), 509-533. 
Borrás, I., \& Lafayette, R. C. (1994). Effects of multimedia courseware subtitling on the speaking performance of college students of French. The Modern Language Journal, 78(1), 61-75.

Cai, W., \& Wu, Y. (2005). Inferring word meaning in second language listening. Hong Kong Journal of Applied Linguistics, 10(2), 1-18.

Carton, A. S. (1971). Inferencing: A process in using and learning language. In P. Pimsleur \& T. Quinn (Eds.), The psychology of second language learning (pp. 45-58). London: Cambridge University Press.

Chapple, L., \& Curtis, A. (2000). Content-based instruction in Hong Kong: Student responses to film. System, 28(3), 419-433.

Chern, C.-L. (1995). Chinese students' word-solving strategies in reading in English. In T. Huckin, M. Haynes, \& J. Coady (Eds.), Second language reading and vocabulary learning (pp. 67-85). Norwood, NJ: Ablex.

Etemadi, A. (2012). Effects of bimodal subtitling of English movies on content comprehension and vocabulary recognition. International Journal of English Linguistics, 2(1), 239-248.

Fraser, C. A. (1999). Lexical processing strategy use and vocabulary learning through reading. Studies in Second Language Acquisition, 21(2), 225-241.

Gilakjani, A. P. (2012). The significant role of multimedia in motivating EFL learners' interest in English language learning. International Journal of Modern Education and Computer Science, 4(4), 57-66.

Ginther, A. (2002). Context and content visuals and performance on listening comprehension stimuli. Language Testing, 19(2), 113-167.

Goh, C. C. (2002). Exploring listening comprehension tactics and their interaction patterns. System, 30(2), 185-206.

Gorjian, B. (2014). The effect of movie subtitling on incidental vocabulary learning among EFL learners. International Journal of Asian Social Science, 4(9), 1013-1026.

Gruba, P. (2006). Playing the videotext: A media literacy perspective on video-mediated L2 listening. Language Learning and Technology, 10(2), 77-92.

Haastrup, K. (1991). Lexical inferencing procedures or talking about words: Receptive procedures in foreign language learning with special reference to English. Tubingen, Germany: Gunter Narr.

Harji, M. B., Woods, P. C., \& Alavi, Z. K. (2010). The effect of viewing subtitled videos on vocabulary learning. Journal of College Teaching \& Learning, 7(9), 37-42.

Hayati, A., \& Mohmedi, F. (2011). The effect of films with and without subtitles on listening comprehension of EFL learners. British Journal of Educational Technology, 42(1), 181-192.

Haynes, M. (1995). Patterns and perils of guessing in second language reading. In T. 
Huckin, M. Haynes, \& J. Coady (Eds.), Second language reading and vocabulary learning (pp. 46-64). Norwood, NJ: Ablex.

Herron, C., Morris, M., Secules, T., \& Curtis, L. (1995). A comparison study of the effects of video-based versus text-based instruction in the foreign language classroom. French Review, 68(5), 775-795.

Howard, B., \& Moore, R. (Directors). (2016). Zootopia [Motion picture]. United State: Walt Disney Pictures.

Hsu, C. K., Hwang, G. J., Chang, Y. T., \& Chang, C. K. (2013). Effects of video caption modes on English listening comprehension and vocabulary acquisition using handheld devices. Journal of Educational Technology \& Society, 16(1), 403-414.

Hulstijn, J. H. (1992). Retention of inferred and given word meanings: Experiments in incidental vocabulary learning. In P. J. L. Arnaud \& H. Béjoint (Eds.), Vocabulary and applied linguistics (pp. 113-125). London: Macmillan.

Hwang, Y., \& Huang, N. P. W. (2010). A study of EFL college students' language anxiety in multimedia environment. International Journal of the Humanities, 8(2), 367378.

Ismaili, M. (2013). The effectiveness of using movies in the EFL classroom: A study conducted at South East European University. Academic Journal of Interdisciplinary Studies, 2(4), 121-132.

Joe, A. (1998). What effects do text-based tasks promoting generation have on incidental vocabulary acquisition? Applied Linguistics, 19(3), 357-377.

Johnstone, J., \& Milne, L. (1995). Scaffolding second language communicative discourse with teacher controlled multimedia. Foreign Language Annals, 28(3), 315-329.

Keating, G. D. (2008). Task effectiveness and word learning in a second language: The involvement load hypothesis on trial. Language Teaching Research, 12(3), 365386.

Kim, K. (2006). Using movies to improve cultural awareness: A case study of the movie Legally blonde. STEM Journal, 7(2), 3-24.

Koolstra, C. M., \& Beentjes, J. W. (1999). Children's vocabulary acquisition in a foreign language through watching subtitled television programs at home. Educational Technology Research and Development, 47(1), 51-60.

Krashen, S. (1989). We acquire vocabulary and spelling by reading: Additional evidence for the input hypothesis. The Modern Language Journal, 73(4), 443-463.

Kwak, N. (2004). The use of animation for elementary school English in Korea (Unpublished master's thesis). Sogang University, Seoul, Korea.

Lee, B. P., \& Cai, W. (2010). The effects of language proficiency on unfamiliar word processing in listening comprehension. Hong Kong Journal of Applied Linguistics, 12(2), 61-82. 
Markham, P. (1999). Captioned videotapes and second-language listening word recognition. Foreign Language Annals, 32(3), 321-328.

Morrison, L. (1996). Talking about words: A study of French as a second language learners' lexical inferencing procedures. Canadian Modern Language Review, 53(1), 4175.

Nagy, W. E., Herman, P., \& Anderson, R. C. (1985). Learning words from context. Reading Research Quarterly, 20(2), 233-253.

Nassaji, H. (2003). L2 vocabulary learning from context: Strategies, knowledge sources, and their relationship with success in L2 lexical inferencing. TESOL Quarterly, 37(4), 645-670.

Nation, I. S. P. (1990). Teaching and learning vocabulary. New York, NY: Newbury House.

Nation, I. S. P. (2001). Learning vocabulary in another language. Cambridge, UK: Cambridge University Press.

Nation, P., \& Meara, P. (2010). Vocabulary. In N. Schmitt (Ed.), An introduction to applied linguistics (pp. 34-52). New York, NY: Routledge.

Ogata, H., Matsuka, Y., El-Bishouty, M. M., \& Yano, Y. (2009). LORAMS: Linking physical objects and videos for capturing and sharing learning experiences towards ubiquitous learning. International Journal of Mobile Learning and Organisation, 3(4), 337-350.

O’malley, J. M., Chamot, A. U., \& Küpper, L. (1989). Listening comprehension strategies in second language acquisition. Applied Linguistics, 10(4), 418-437.

Oxford, R. L., \& Scarcella, R. C. (1994). Second language vocabulary learning among adults: State of the art in vocabulary instruction. System, 22(2), 231-243.

Paribakht, S., \& Wesche, M. (1999). Reading and "incidental" L2 vocabulary acquisition: An introspective study of lexical inferencing. Studies in Second Language Acquisition, 21(2), 195-224.

Richards, J. (1985). The context of language teaching. New York, NY: Cambridge University Press.

Rott, S. (1999). The effect of exposure frequency on intermediate language learners' incidental vocabulary acquisition and retention through reading. Studies in Second Language Acquisition, 21(4), 589-619.

Shim, J., \& Baik, J. (1997). Using movies in language classrooms: Rationale and methods. English Education, 52(1), 59-88.

Stephens, J. L. (2001). Teaching culture and improving language skills through a cinematic lens: A course on Spanish film in the undergraduate Spanish curriculum. $A D F L$ Bulletin, 33(1), 22-25.

Vandergrift, L. (1997). The comprehension strategies of second language (French) 
listeners: A descriptive study. Foreign Language Annals, 30(3), 387-409.

Waring, R., \& Takaki, M. (2003). At what rate do learners learn and retain new vocabulary from reading a graded reader? Reading in a Foreign Language, 15(2), 130-163.

Warschauer, M. (1997). Computer-assisted language learning: Theory and practice. Modern Language Journal, 84(4), 470-480.

Watts, C. (1989). Interactive video: What the students say. Calico Journal, 7(1), 17-20.

Webb, S. (2007). The effects of repetition on vocabulary knowledge. Applied Linguistics, 28(1), 46-65.

Webb, S. (2010). A corpus driven study of the potential for vocabulary learning through watching movies. International Journal of Corpus Linguistics, 15(4), 497-519.

Webb, S., \& Rodgers, M. P. (2009). The lexical coverage of movies. Applied Linguistics, 30(3), 407-427.

Wilson, C. C. (2000). Practical aspects of using video in the foreign language classroom. The TESL Journal, 6(11), 36-41.

Wittrock, M. C., Marks, C., \& Doctorow, M. (1975). Reading as a generative process. Journal of Educational Psychology, 67(4), 484-489.

Yang, J., \& Kim, M. (2010). Understanding and learning of English vocabulary based on American TV drama. The Journal of English Education, 40, 31-56.

Yum, M.-S., \& Kahng, Y.-K. (2007). An effect of using movies in English on vocabulary power and interest in primary English education. STEM Journal, 8(2), 55-82.

\section{APPENDIX}

Lexical Inferencing Task

The following excerpts are from the script of the movie Zootopia. Read the excerpts and make your best guess for the underlined words.

$\# 1$

[Chief Bogo, the cape buffalo chief of police enters Zootopia Police Department.]

Chief Bogo:

Finally, we have fourteen missing (1) mammal cases - all (2) predators - from a giant polar bear to a teensy little otter, and City Hall is right up my tail to find them! This is (3) priority number one. Assignments: Officers Grizzoli, Fangmeyer, Delgato; your teams take missing mammals from the Rainforest District... And finally our first bunny: Officer Hopps... [Judy anxiously awaits for her assignment; Chief 
Bogo sighs, giving a blank stare] parking duty. Dismissed. [Judy shows signs of confusion.]

\#2

[In the cafe, the owner, Jerry Jumbeaux, Jr., an elephant, is at the counter taking orders. Judy enters and sees Nick talking to Jerry.]

Jerry Jumbeaux Jr.: $\quad$ Look, you probably can't read, fox, but the sign says "We reserve the right to refuse service to anyone", so beat it! [Judy steps forward]

Judy Hopps:

Well, I don't wanna cause you any trouble but, I believe (4) scooping ice cream with an ungloved trunk is a class-three health code (5) violation. Which is kind of a big deal. Of course I can let you off with a (6) warning if you glove those trunks and, I don't know, finish selling this nice dad and his son a... [to Nick] What was it?

Nick Wilde: $\quad$ A jumbo pop. Please. (...) Thank you so much. Oh no, are you kidding me? I don't have my wallet! I'd lose my head if it weren't (7) attached to my neck. Thanks anyway.

[Judy slams a twenty dollar bill on the counter.]

Nick Wilde:

Officer, I can't thank you enough. So kind, really. Can I pay you back?

Judy Hopps: $\quad$ Oh no, my (8) treat. It just - you know, it burns me up to see folks with such backward attitudes toward foxes. I just wanna say that you're a great dad and just a... A real articulate fella

Nick Wilde:

Well that is high (9) praise. It's rare that I find someone so non-patronizing.

\#3

[They arrive at Tundratown Limo Service and Judy tugs on the lock on the gate.]

Judy Hopps: $\quad$ Closed. Great. 
Nick Wilde:

Hmm. And I will betcha you don't have a (10) warrant to get in, hmm?

Judy Hopps:

You (11) wasted the day on purpose!

Nick Wilde:

Madam, [points to his police sticker] I have a (12) fake badge. I would never (14) impede your pretend (14) investigation.

Judy Hopps: It's not a "pretend investigation". [takes out the Otterton picture] Look, see? See him? This otter is missing.

Nick Wilde:Well, then they should've gotten a real cop to find him.

Judy Hopps: $\quad$ [really upset, puts the picture away] What is your problem? Does seeing me fail somehow make you feel better about your own sad, (15) miserable life?

\#4

[Judy leads the Zootopia Police Department to the sky tram.]

Judy Hopps: I thought this was just a missing mammal case, but it's way bigger. Mr. Otterton did not just (16) disappear. I believe he, and this jaguar, they went (17) savage, sir.

Chief Bogo:

Savage? This isn't the stone age, Hopps. Animals don't "go savage". (...)

Judy Hopps:

Sir, I know what I saw. He almost killed us!

Chief Bogo:

Or maybe any (18) aggressive predator looks "savage" to you rabbits. (...)

Judy Hopps:

No. Wait! Sir, I'm not the only one who saw him. Nick!

Chief Bogo:

You think I'm gonna believe a fox?

Judy Hopps:

Well he was a key (19) witness, and I... 
Chief Bogo:

Two days to find the otter, or you quit. That was the deal. [holds out his hoof] Badge. [Nick looks at Judy and Chief Bogo shocked.] (...)

Nick Wilde:

She will not be giving you that badge. Look, you gave her a... a clown vest, a three-wheeled joke-mobile, and two days to solve a case you guys haven't (20) cracked in two weeks? Here's the thing, chief. You gave her the 48 hours, so technically we still have... [counts and holds out his paws] ten left to find our Mr. Otterton, and that is exactly what we're gonna do.

Applicable level: university

Keywords: multimedia, movie, lexical knowledge, vocabulary learning, lexical inference

Lee, Jin Hyung

The Department of English Language and Literature

Korea University

145 Anam-ro, Seongbuk-gu,

Seoul, 20841, Korea

E-mail: jinhlee@korea.ac.kr

Received: October 15, 2018

Revised version: November 14, 2018

Accepted: November 25, 2018 